Mark V. Williams, MD

Editor-in-Chief, Journal of Hospital Medicine

\section{Two Years Done and More Evolution}

We live in a moment of history where change is so speeded up that we begin to see the present only when it is already disappearing.-R. D. Laing

T wo years ago we published the first issue of the Journal of Hospital Medicine and declared, "Our goal is that JHM become the premier forum for peer-reviewed research articles and evidence-based reviews in the specialty of hospital medicine." ${ }^{1}$ That first issue was just one of many steps toward this ambition. At the completion of its first year, JHM was selected for indexing and inclusion in the National Library of Medicine's Medical Literature Analysis and Retrieval System Online (MEDLINE), the primary component of PubMed ${ }^{\circledR}$. Following this huge step, we welcomed a remarkable increase in submissions and will have exceeded 300 in our second year, an approximately $50 \%$ increase from our first year!

As important, JHM quickly became a valuable benefit of membership in the Society of Hospital Medicine, and the innumerable compliments received by the staff reflect the diligent efforts of a remarkable editorial staff and work by our reviewers. With profound gratitude we list on page 86 these 325 reviewers who donated their priceless time and expertise to enhancing the quality of the manuscripts. To handle the marked increase in submissions, we are expanding and modifying our editorial staff. Please welcome Sunil Kripalani (Vanderbilt) and Daniel Brotman (Johns Hopkins), who join our previous six associate editors and all eight will now serve as JHM's deputy editors. Seven new associate editors also join our team. Among them, Tom Baudendistel (California Pacific Medical Center, San Francisco), Eric Alper (UMass Memorial Health Care, Worcester), Brian Harte (Cleveland Clinic), and Rehan Qayyum (Johns Hopkins) will all focus on optimizing content for practicing hospitalists. Paul Aronowitz will continue to develop our Images section as an associate editor. Recognizing the growing number of pediatric hospitalists, Lisa Zauotis (Childrens Hospital of Philadelphia) and Erin Stucky (Children's Hospital San Diego) join $J H M$ as the other 2 new associate editors. Finally, we welcome new Editorial Board members Mary C. Ottolini (Children's National Medical Center), Douglas Carlson (St. Louis Children's Hospital), and Daniel Rauch (NYU Children's Hospital). The welcome addition of these nationally recognized academicians prepares us for continued growth in manuscript submissions to JHM.

Although we could not excel without the editors, reviewers and our terrific new managing editor, Phaedra McGuinness, we would not survive without the authors who submit their manuscripts to $J H M$ - they are responsible for the caliber of the journal, and we are immensely indebted to them. Originally, we hoped to 
"include individuals involved in all aspects of hos-

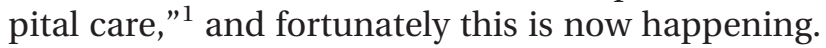
Complementing hospitalists are nurses and pharmacists ${ }^{2}$ who recognize the importance of teamwork in the care of hospitalized patients. I encourage all members of the hospital care team to send us the results of their research, teaching, and quality improvement efforts.

As the specialty of hospital medicine continues to evolve, now with more than 20,000 hospitalists, $J H M$ will develop with it. I am honored and grateful to collaborate with such a remarkable group of colleagues as we build the premier journal for the fastest growing specialty in the history of medicine in the United States. On to year 3!

\section{REFERENCES}

1. Williams MV. Hospital medicine's evolution-the next steps. J Hosp Med. 2006;1:1-2.

2. Cobaugh DJ, Amin A, Bookwalter T, et al. ASHP-SHM joint statement on hospitalist-pharmacist collaboration. Am J Health-Syst Pharm. 2008;65:260-263.

P.S. Our tenuous hold on life confronted me this past Thanksgiving holiday. A fellow hospitalist and dear friend died unexpectedly. Two years before, he posted on the wall of the office shared with his colleagues the following quote:

What we do for ourselves fades, but what we do for another may be etched into eternity.

The smile and humanity of John Allen Garner (1963-2007) is etched into the lives of his family, many friends and colleagues, and innumerable grateful patients. 